\title{
Effects of transcranial photobiomodulation and methylene blue on biochemical and behavioral profiles in mice stress model
}

\author{
Reza Meynaghizadeh-Zargar ${ }^{1,2} \cdot$ Saeed Sadigh-Eteghad ${ }^{1} \cdot$ Gisou Mohaddes $^{1} \cdot$ Farzad Salehpour $^{1}$. \\ Seyed Hossein Rasta ${ }^{1,2,3,4}$ (D)
}

Received: 9 March 2019 / Accepted: 23 July 2019 / Published online: 1 August 2019

(C) The Author(s) 2019

\begin{abstract}
The effectiveness of transcranial photobiomodulation (tPBM) and methylene Blue (MB) in treating learning and memory impairments is previously reported. In this study, we investigated the effect of tPBM and MB in combination or alone on unpredictable chronic mild stress (UCMS)-induced learning and memory impairments in mice. Fifty-five male BALB/c mice were randomly allocated to five groups: control, laser sham + normal saline (NS), tPBM + NS, laser sham + MB, and tPBM + MB. All groups except the control underwent UCMS and were treated simultaneously for 4 weeks. Elevated plus maze (EPM) was used to evaluate anxiety-like behaviors. Novel object recognition (NOR) test and Barnes maze tests were used to evaluate learning and memory function. The serum cortisol and brain nitric oxide (NO), reactive oxygen species (ROS), total antioxidant capacity (TAC), glutathione peroxidase (GPx), and superoxide dismutase (SOD) levels were measured by spectrophotometric methods. Behavioral tests revealed that UCMS impaired learning and memory, and treatment with PBM, MB, and their combination reversed these impairments. Levels of NO, ROS, SOD activity in brain, and serum cortisol levels significantly increased while brain GPx activity and total antioxidant capacity significantly decreased in the sham + NS animals when compared with the controls. A significant improvement was observed in treatment groups due to reversion of the aforementioned molecular analysis caused by UCMS when it was compared with control levels. Both TPBM and MB in combination or alone have significant therapeutic effects on learning and memory impairments in UCMS-received animals.
\end{abstract}

Keywords Chronic mild stress $\cdot$ Photobiomodulation $\cdot$ Methylene blue $\cdot$ Learning and memory $\cdot$ Anxiety $\cdot$ Near-infrared laser

\section{Introduction}

Due to fast-growing modernization and repeated and/or persistent exposure to social challenges, chronic stress has been considered to be a crucial mental health challenge and developing efficient, noninvasive, and low-cost therapeutic interventions is urgently required [1]. Chronic stress is a major

Seyed Hossein Rasta

s.h.rasta@abdn.ac.uk

1 Neurosciences Research Center (NSRC), Tabriz University of Medical Sciences, Tabriz 51666, Iran

2 Department of Medical Physics, Tabriz University of Medical Sciences, Tabriz 51666, Iran

3 Department of Medical Bioengineering, Tabriz University of Medical Sciences, Tabriz 51666, Iran

4 School of Medical Sciences, University of Aberdeen, Aberdeen AB25 2ZD, UK health concern and is considered to be a risk factor for developing several emotional distress such as depression, anxiety, and cognitive-related dysfunctions such as learning and memory impairments [2]. Mitochondrial dysfunction is involved as an underlying mechanism associated with chronic stress [3]. Mitochondrial oxidative phosphorylation is the main source of reactive oxygen species (ROS) production, and the electron transport chain (ETC) itself is susceptible to be damaged by overproduction of ROS [4]. Given this, the oxidative damage induced by chronic stress is the cause of the mitochondrial impairment [3]. A study on mice showed that chronic stress resulted in impaired spatial learning and memory as evaluated by the Morris water maze (MWM) task [5].

Photobiomodulation (PBM) therapy involves the application of low-power light from red to near-infrared (NIR) spectrums $(600-1100 \mathrm{~nm}$; powers $<500 \mathrm{~mW})$ [6]. Transcranial PBM (tPMB) therapy is a noninvasive intervention and its neuroprotective potential is related to nonthermal and neurostimulatory aspects [7]. Recently, there is a growing 
interest in expanding the indications for the brain application of tPMB including neurological and psychiatric disorders [8]. It has also been revealed that $\mathrm{PBBM}$ is potential of decreasing the hippocampal oxidative injury by improving the antioxidant defense system in sleep-deprived mice [9]. PBM has a significant effect on reduction of $A \beta$ plaques and memory improvements in treated animals after $A \beta$ toxicity in hippocampus [10]. It was shown that the dose of $8 \mathrm{~J} / \mathrm{cm}^{2}$ is more beneficial in reversing anxiety- and depression-like behaviors to normal condition [11]. The combined effect of tPBM and metabolic modulators (e.g., pyruvate or lactate) has been investigated both in vitro and in vivo. Findings of this study confirmed that the combinational treatment reversed the impaired memory of animals to a normal level [12]. The beneficial applications of PBM combined with vitamin A and iron nanoparticles were also demonstrated in animal models of wound $[13,14]$. A randomized studies in young adults confirmed that PBM combined with acute aerobic exercise is beneficial for cognitive enhancement [15].

Methylene blue (MB) is a reduction-oxidation agent that at low doses stimulates mitochondrial respiration by donating electrons to the ETC [16]. MB as a mitochondrial neuroprotective agent readily crosses the blood-brain barrier (BBB) and affects neural cells [17]. A substantial body of evidence supports that systemically administered low-dose MB improves neuronal mitochondrial cytochrome $\mathrm{c}$ oxidase (COX) activity, oxygen consumption, brain glucose utilization, and adenosine triphosphate (ATP) synthesis [18, 19]. Moreover, the protective action of MB against neuronal oxidative stress damage has been reported [20]. Recently, the therapeutic effect of MB in combination with hypothermia has been examined and improvement of spatial learning and memory was observed in the combined treatment rats when compared with single-treatment groups [21]. It has been suggested that the interaction of $\mathrm{TPBM}$ and MP with the mitochondria leads to the stimulation of ETC in the brain tissue [1]. It seems that combined utilization of TPBM and MB can have beneficial effects on damaged neuronal tissue.

In the current study, we aimed to investigate the potential neuroprotective action of TPBM (as a photon donor) and MB (as an electron donor) on mitochondrial dysfunction and spatial and episodic-like memory impairment in the mice model of unpredictable chronic mild stress (UCMS).

\section{Material and methods}

\section{Animals and study design}

Sixty male Balb/c mice, 8 weeks of age (25-30 g), were obtained from the animal house of Tabriz University of Medical Sciences (TUMS) (Tabriz, Iran). Animals were socially housed in standard cages (five mice per cage) in a 12-h light/12-h dark and temperature $\left(23-25^{\circ} \mathrm{C}\right)$ controlled condition, with the food and water ad libitum. After 1 week of acclimatization, mice were randomized into the control $(n=$ $12)$ and stress-induced groups $(n=48)$. The stress was induced by exposure to the UCMS paradigm for four consecutive weeks. Then, UCMS mice were randomly divided into 4 groups ( $n=12$ in each group) as follows: (i) sham (UCMS + laser probe without irradiation) + normal saline (NS), (ii) $\mathrm{tPBM}+\mathrm{NS}$, (iii) sham + MB, and (iv) $\mathrm{tPBM}+\mathrm{MB}$. A volume of $0.2 \mathrm{~mL}$ of NS was injected intraperitoneally for each mouse in the sham + NS and tPBM + NS groups.

\section{UCMS paradigm}

In order to induce stress, mice were subjected to the UCMS paradigm for 4 weeks according to the method proposed by Wang et al. [5]. Briefly, each week of the stress regime consisted of different social and environmental stressors 2-3 times per day. The eight stress conditions were as follows: (1) food deprivation for $24 \mathrm{~h}$, (2) water deprivation for $24 \mathrm{~h}$ (with exposure to empty bottle for the last $1 \mathrm{~h}$ ), (3) overnight illumination, (4) removal of sawdust for $24 \mathrm{~h}$, (5) wet bedding for $24 \mathrm{~h}$, (6) forced swimming at $18{ }^{\circ} \mathrm{C}$ water for $6 \mathrm{~min}$, (7) tail nipping for $1 \mathrm{~min}$, and (8) physical restraint for $2 \mathrm{~h}$. A timeline of the procedures is depicted in Fig. 1.

\section{Laser irradiation}

A diode GaAlAs laser (Thor Photomedicine, Chesham, UK) at 810-nm wavelength was applied for irradiation sessions. The laser's operation mode was Pulsed Wave (PW) on $10 \mathrm{~Hz}, 88 \%$ duty cycle, and average irradiance of $4.75 \mathrm{~W} /$ $\mathrm{cm}^{2}$. A fluence of $8 \mathrm{~J} / \mathrm{cm}^{2}$ was delivered to the cortical surface, as previously described [22]. For transcranial laser irradiation, the mouse was positioned on a plate and laser probe placed over the head that covered the entire brain. Laser irradiation was performed three times a week over a period of 4 weeks. The UCMS group as sham-treated mice underwent identical laser treatment but did not receive any laser irradiation.

\section{Methylene blue treatment}

The dye MB was obtained from Sigma-Aldrich (St. Louis, MO, USA). Mice in the sham + MB and $\mathrm{tPMB}+$ MB groups received a daily dose of MB $(0.5 \mathrm{mg} / \mathrm{kg}$ body weight; Intraperitoneal) for 4 consecutive weeks [23]. To avoid unwanted toxic effects of laser irradiation after MB administration [24], mice in the $\mathrm{PMB}+\mathrm{MB}$ group initially received laser treatment and after $2 \mathrm{~h}$, MB was injected. 


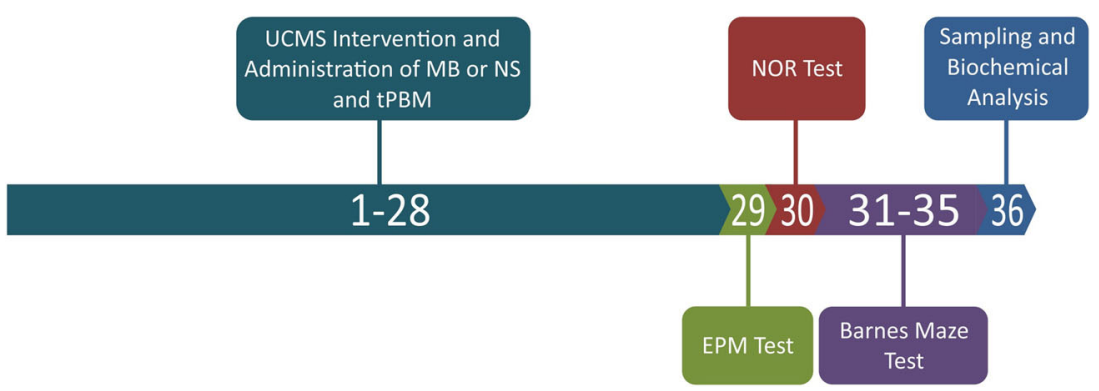

Fig. 1 The schematic view of the study including the application of UCMS and TPBM and MB treatments. EPM and NOR behavioral tests were performed on day 29 and day 30 , respectively. Barnes maze test was also performed in days 31 to 35 . At the end of this study (day 36), brain

\section{Behavioral analysis}

\section{Elevated plus maze test}

The elevated plus maze (EPM) test evaluates anxiety-like and exploratory behaviors in rodents and was carried out with the same method shown previously by Patel and Hillard [25]. Briefly, the apparatus was comprised of two open $(30 \times$ $5 \mathrm{~cm})$ and two closed arms $(30 \times 5 \times 15 \mathrm{~cm})$ extending from a central platform $(5 \times 5 \mathrm{~cm})$ and elevated $40 \mathrm{~cm}$ from the floor. The maze was positioned in the center of the room and a video camera was located above the apparatus. Each mouse was placed in the center of the maze, facing an enclosed arm, and was allowed to freely explore it for $5 \mathrm{~min}$. The maze was cleaned with $70 \%$ ethanol solution between the individual testing. All procedures took place in the morning (between 10:00 and 12:00 AM), in a room with controlled temperature and light. The following behaviors were considered: (a) the percentage of time spent in open arms (\%OAT), (b) the percentage of entries to open arm (\%OAE), and (c) the total arm entries (TAE). The recordings were analyzed using a fully automated video-tracking program Etho Vision ${ }^{\mathrm{TM}}$ (Noldus, The Netherlands).

\section{Novel object recognition test}

The novel object recognition (NOR) test is a cognitive paradigm that evaluates episodic-like memory. The test apparatus consisted of a Plexiglas open-field box $(30 \times 30 \times 30 \mathrm{~cm})$ and assembled objects (LEGO® blocks). The NOR test included habituation, training, and retention sessions. Before the training session, each mouse was habituated to the empty arena for $10 \mathrm{~min}$ on the first day. One day after habituation, each mouse was subjected to a training session in which two similar objects $\left(\mathrm{A}\right.$ and $\left.\mathrm{A}^{\prime}\right)$ were located in the arena and the animal was allowed to explore the arena and objects for $10 \mathrm{~min}$. Retention session performed $24 \mathrm{~h}$ after training, in this phase, the mouse was returned to the same task, but one of the familiar objects (A or $A^{\prime}$ ) was replaced by a novel one (B). After each trial, the samples were prepared for molecular analysis. UCMS, unpredictable chronic mild stress; tPBM, transcranial photobiomodulation; MB, methylene blue; EPM, elevated plus maze; NOR, novel object recognition; NS, normal saline

apparatus was cleaned with $70 \%$ ethanol. The locomotor activity and discrimination index (DI) were recorded by a video camera fixed above the apparatus and scored using fully automated video-tracking program Etho Vision ${ }^{\mathrm{TM}}$ (Noldus, The Netherlands) [26]. DI was calculated by the following equation $\mathrm{DI}=(N-F) /(N+F)$, where $N$ is the time of novel object exploration and $F$ is the time of familiar object exploration.

\section{Barnes maze task}

The Barnes test was utilized to evaluate spatial learning and memory. The procedure was as described previously [22]. The test had three sessions, adaptation, training, and a probe trial which was performed during 5 days. As adaptation and training sessions, each mouse was placed in the center of the maze and allowed to explore the maze for $3 \mathrm{~min}$ in the presence of a negative sound stimulus ( $80 \mathrm{~dB})$, when the animal entered the escape box, the buzzer was stopped and the animal allowed to remain in it for $1 \mathrm{~min}$. The maze was cleaned between the trials with a $70 \%$ ethanol solution to prevent odor cues. On the fifth day, a probe trial was carried out, that is, the escape box was removed and mouse was placed in the center of the maze for free activity. The parameters of interest were (a) the escape latency time (the time to reach the target hole) during the training sessions and (b) the time spent in the target quadrant, and (c) correct/wrong relative time during probe session, which were measured using a video tracking program Etho Vision $^{\mathrm{TM}}$ (Noldus, The Netherlands).

\section{Biochemical analysis}

\section{Sampling}

Twenty-four hours after last behavioral test, mice in the experimental groups were decapitated after deep anesthesia with a mixture of ketamine $(75 \mathrm{mg} / \mathrm{kg})$ and xylazine $(10 \mathrm{mg} / \mathrm{kg})$. For each mouse, blood sample was taken and centrifuged for 
serum obtaining. The brain tissues were immediately removed and kept in the refrigerator under $-70^{\circ} \mathrm{C}$.

\section{ROS production}

Dichlorohydrofluorescein diacetate (DCFDA) was utilized as a fluorescent dye to measure the ROS production level in the brain. The mitochondria were incubated with 2-mM DCFDA at $37^{\circ} \mathrm{C}$ for $20 \mathrm{~min}$. A fluorescence microplate reader was used to determine the fluorescence intensity. ROS levels were represented as fluorescence intensity and normalized to samples protein.

\section{Nitric oxide production}

Sample preparation started with the pulverization of brain tissue with liquid nitrogen, and then, $30 \mathrm{~s}$ of homogenization with $1 \mathrm{~mL}$ of cold phosphate-buffered saline (PBS) on the ice was done. The resultants were centrifuged for $10 \mathrm{~min}$ at $4{ }^{\circ} \mathrm{C}(10,000 \mathrm{r} / \mathrm{min})$ and were kept at $-80^{\circ} \mathrm{C}$. The enzymelinked immunosorbent assay (ELISA) kit of mouse nitric oxide (NO) was provided by Hangzhou Eastbiopharm Co., Ltd. (Hangzhou, China). The manufacturer's ELISA kit guidelines were used to perform the measurements. NO levels were stated as micromoles per milligram of protein.

\section{Antioxidant activity measurement}

The brain samples were homogenized with $1.15 \% \mathrm{KCl}$ and centrifuged for $10 \mathrm{~min}$ at $4{ }^{\circ} \mathrm{C}(10,000 \mathrm{r} / \mathrm{min})$ and kept under $-80^{\circ} \mathrm{C}$. RANSOD (Randox Laboratories Ltd., Crumlin, UK) laboratory kit was utilized to determine the activity of superoxide dismutase (SOD). A spectrophotometer was used to measure the absorbance at 505-nm wavelength, as stated in the manufacturer's guidelines. Glutathione peroxidase (GPx) activity of cerebral tissue was measured using the RANSOD (Randox Laboratories Ltd., Crumlin, UK) assay kit. In order to calculate the concentration of GPx, a spectrophotometer was utilized to measure the reduction in absorbance at $340 \mathrm{~nm}\left(37^{\circ} \mathrm{C}\right)$ [27]. Randox total antioxidant status kit (Randox Laboratories Ltd., Crumlin, UK) was also used to measure the total antioxidant capacity (TAC). Changes in the absorbance at $600 \mathrm{~nm}$ caused by the variation in the sample's color were measured [28].

The activity values of GPX and SOD in the cerebral tissue were stated as units per milligram of protein. The value of $\mathrm{TAC}$ in the brain was also stated as millimoles per liter.

\section{Serum cortisol levels determination}

The serum cortisol level was measured using a cortisol-specific kit (Catalog No. RE52611, from the IBL International Cortisol Saliva, Germany), according to the manufacturer's instructions.
To avoid fluctuations in cortisol concentrations due to circadian rhythms, blood samples were collected in the morning.

\section{Statistical analysis}

All analyzed data were presented as mean \pm standard error of the mean (SEM). One-way analysis of variance (ANOVA) followed by the Tukey post hoc test was utilized to compare the differences between groups. Moreover, to draw a comparison between groups in the Barnes maze test, the two-way repeated measurement ANOVA was utilized. The statistical analyses were carried out using GraphPad Prism software (version 6), and $p<0.05$ was considered to be significant.

\section{Results}

\section{Effect of TPBM and MB on anxiety-like behaviors in the EPM test}

Statistical analysis revealed that UCMS significantly decreased both \%OAT $(p<0.01)$ and \%OAE $(p<0.0001)$ in the EPM test. However, tPBM or MB alone and in combination significantly increased both the \%OAT and \%OAE when compared with the sham + NS group. (Fig. 2). In addition, there was no statistically significant difference between groups in TAE in this test (data not shown).

\section{Effect of tPBM and MB on episodic memory in the novel object recognition test}

NOR test analysis showed that there was no significant difference between the novel and familiar object exploration time in the sham + NS group, which indicated episodic memory impairment. Whereas, both $\mathrm{tPBM}(p<0.01)$ and MB $(p<0.001)$ treatments significantly increased novel object exploration time. Moreover, the tPBM + NS $(p<0.001)$, sham + MB $(p<0.01)$, and $\mathrm{tPMB}+\mathrm{MB}(p<0.001)$ groups showed a significant increase in DI, while the sham + NS group with negative values had lower DI than the controls $(p<0.0001)$, indicating an impairment in episodic memory (Fig. 3). Furthermore, there were no significant differences between groups in locomotor activity and total observations in this test (data not shown).

\section{Effect of tPBM and MB on spatial learning and memory in the Barnes maze test}

Results analysis showed a decrease in the latency time during 4 days of training in all groups. The sham + NS animals had the highest latency time on day 4 . These data suggest that UCMS induction impairs spatial learning performance, whereas both tPBM and MB treatments significantly $(p<0.05)$ increased latency time when compared with the Sham + NS animals (Fig.4). 


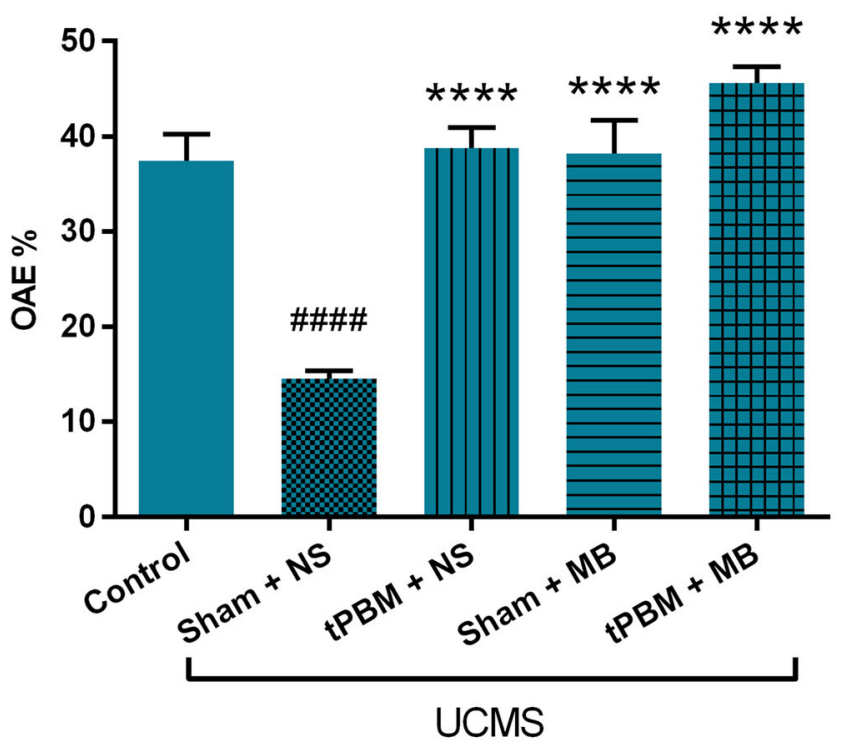

Fig. 2 The effect of treatments on UCMS in anxiety-like behavior in EPM task ${ }^{\# \# \#} p<0.0001$ and ${ }^{\# \#} p<0.01$ when compared with the controls, and $* p<0.05, * * * p<0.001$, and $* * * * p<0.0001$ when compared with the sham + NS group. MB, methylene blue; NS, normal saline;

The time spent of the sham + NS animals in the target quadrant was significantly $(p<0.01)$ lesser than the control group in probe session. The correct/wrong relative time in the sham + NS animals was significantly $(p<0.001)$ lower than the control group. Moreover, the tPBM + NS $(p<0.05)$, sham $+\mathrm{MB}(p<0.05)$, and $\mathrm{PMB}+\mathrm{MB}$ $(p<0.001)$ groups had a significantly higher correct/wrong relative time when compared with the sham + NS group (Fig. 5).

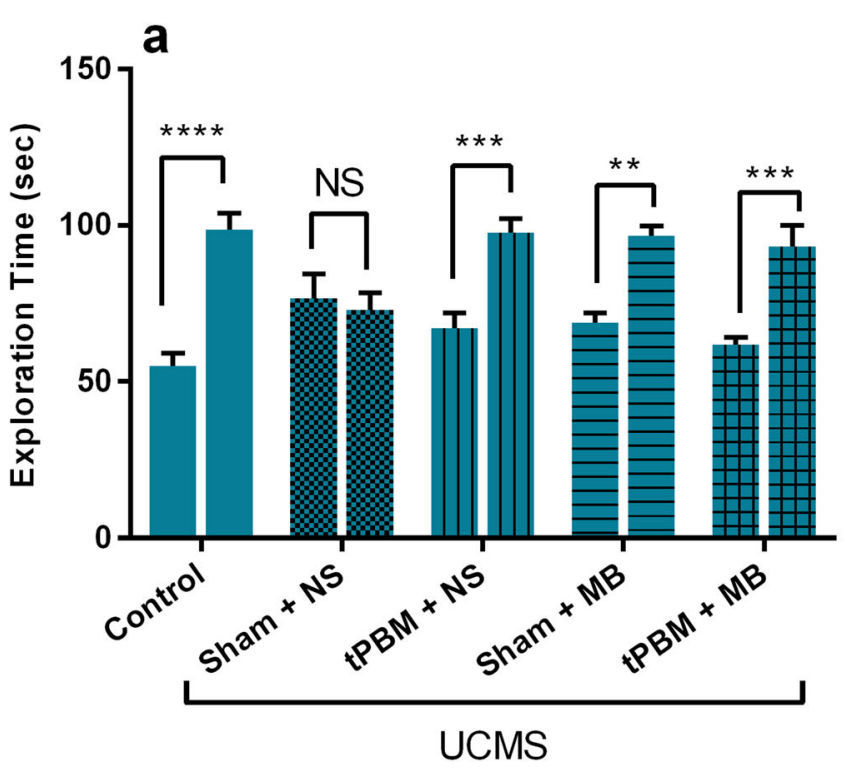

Fig. 3 The effect of treatments on UCMS in episodic memory in the NOR test. a The exploration time of the novel object. The left and right columns of each group represent the exploration time of familiar and novel object, respectively. $* * p<0.01$, *** $p<0.001$, and $* * * * p<0.0001$ between the novel and the familiar exploration time of

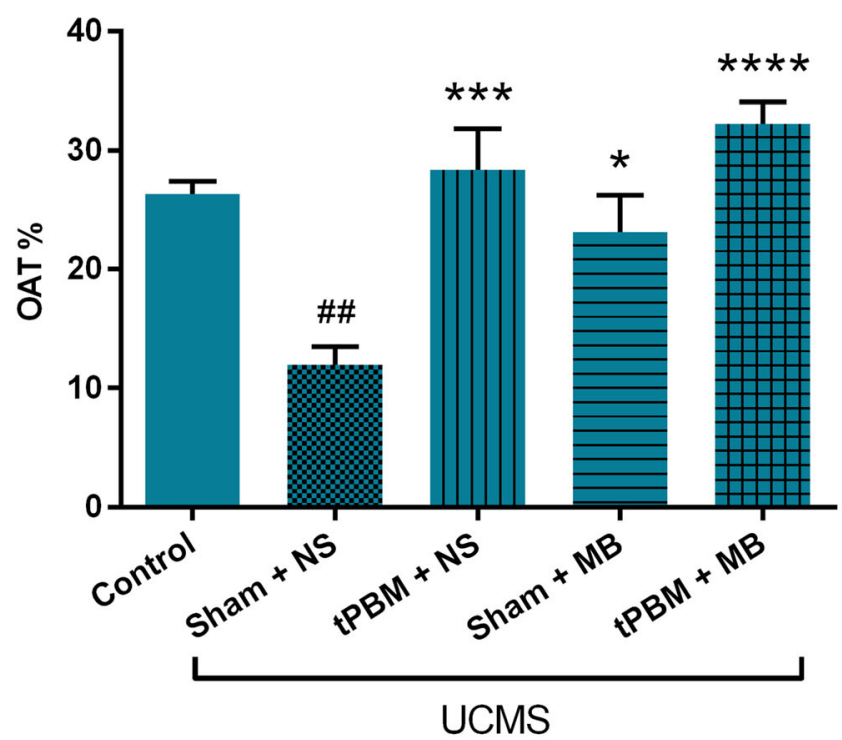

OAE, open arm entry; OAT, open arm time; tPBM, transcranial photobiomodulation; UCMS, unpredictable chronic mild stress; EPM, elevated plus maze

\section{Effect of tPBM and MB on serum cortisol levels}

Results analysis revealed that treatment with $\mathrm{PBBM}$ and $\mathrm{PBBM}$ + MB had a significant effect on serum levels of cortisol in UCMS-received animals. Several comparisons between groups indicated that serum level of cortisol was significantly higher in the sham + NS animals $(p<0.0001)$ and treatment with tPBM $(p<0.01)$ and combined therapy $(p<0.0001)$ could significantly reduce it. Combination therapy with $\mathrm{MB}$

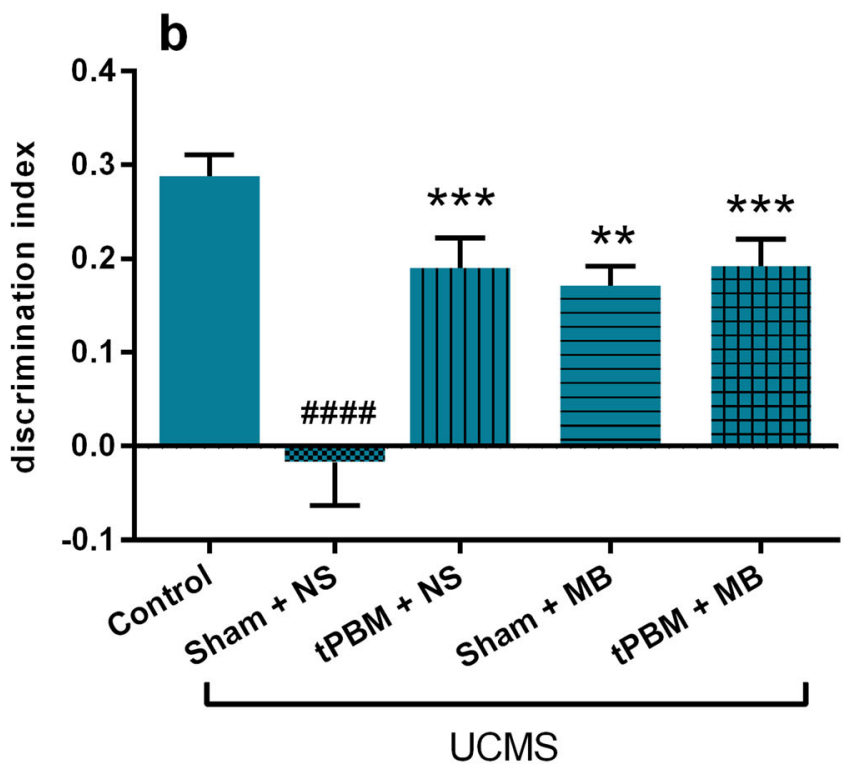

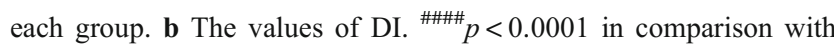
control group and $* * p<0.01$ and $* * * p<0.001$ in comparison with sham + NS group. MB, methylene blue; NS, normal saline; tPBM, transcranial photobiomodulation; UCMS, unpredictable chronic mild stress; NOR, novel object recognition; DI, discrimination index 
Fig. 4 The escape latency time during 4 days in the study groups. ${ }^{\#} p<0.05$ when compared with control animals and $* p<0.05$ compared with sham + NS group on the corresponding days. MB, methylene blue; NS, normal saline; tPBM, transcranial photobiomodulation; UCMS, unpredictable chronic mild stress

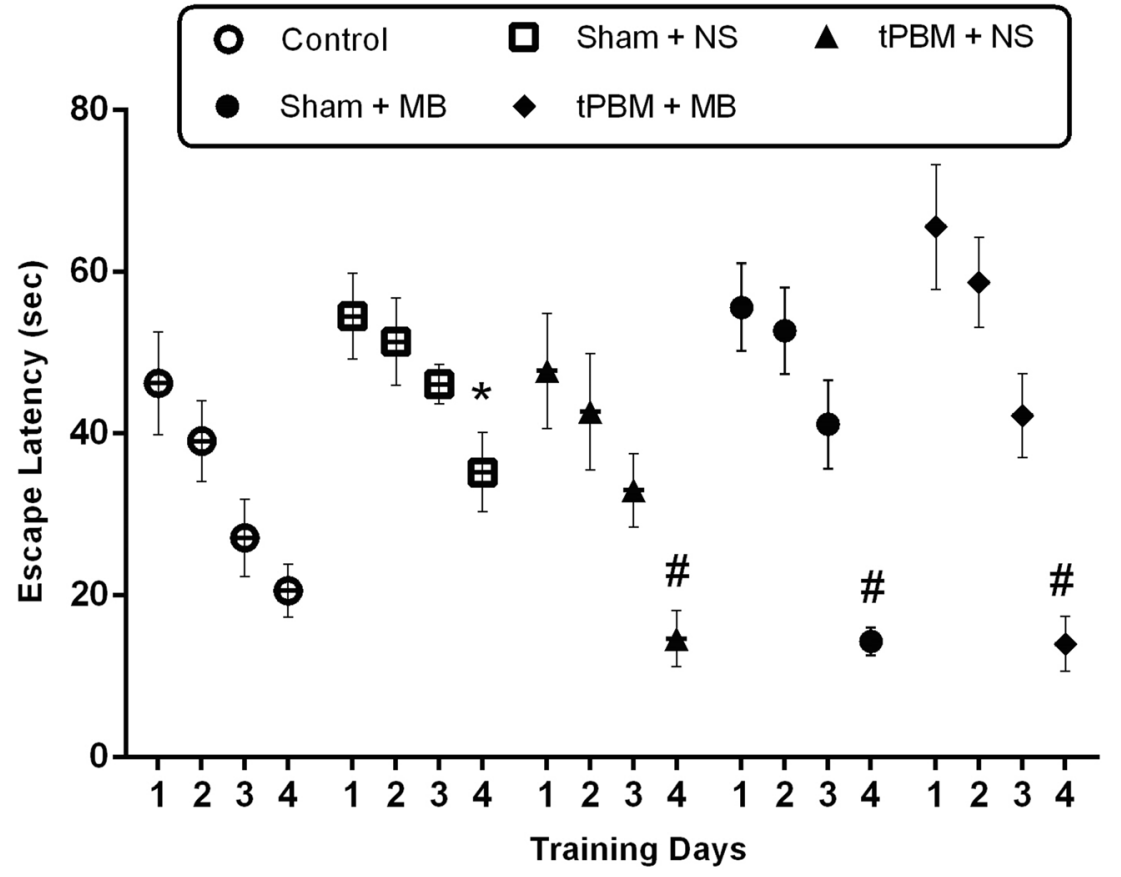

and tPBM also significantly $(p<0.001)$ decreased serum levels of cortisol when compared with single therapy (Fig. 6).

\section{Effect of tPBM and MB on brain NO levels}

Results showed that treatment with $\mathrm{PBBM}$ and MB had a significant effect on brain NO levels in the UCMS-received animals. Several comparisons between groups indicated that NO level was significantly higher in the sham + NS animals when

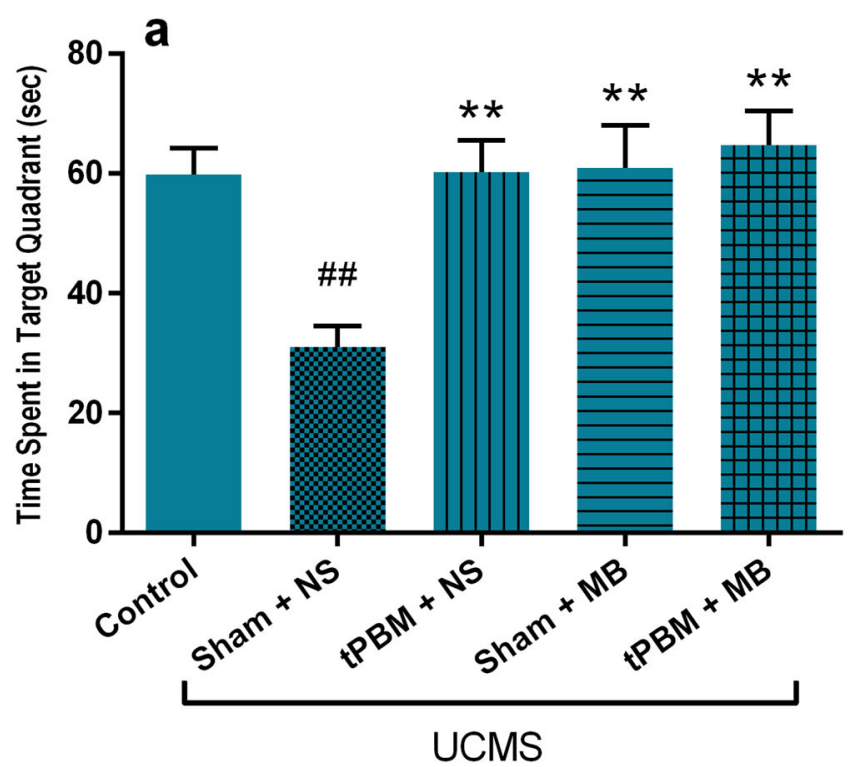

Fig. 5 The evaluation of short-term spatial memory in probe session of Barnes maze test. a The time spent in the target quadrant. b Correct/ wrong relative time. ${ }^{\# \#} p<0.01$ and ${ }^{\# \# \#} p<0.001$ in comparison with control animals and $* p<0.05, * * p<0.01$, and $* * * p<0.001$ in comparison compared with the control group $(p<0.0001)$, and treatment with MB and $\mathrm{PBBM}$ lonely or in their combination could significantly decrease the level of NO in the brain (Fig.7).

\section{Effect of $\mathrm{TPBM}$ and MB on the brain ROS}

The analysis of results revealed that treatment with $\mathrm{APBM}$ and MB in UCMS-received animals had a significant effect on brain ROS levels. Comparisons between groups indicated that

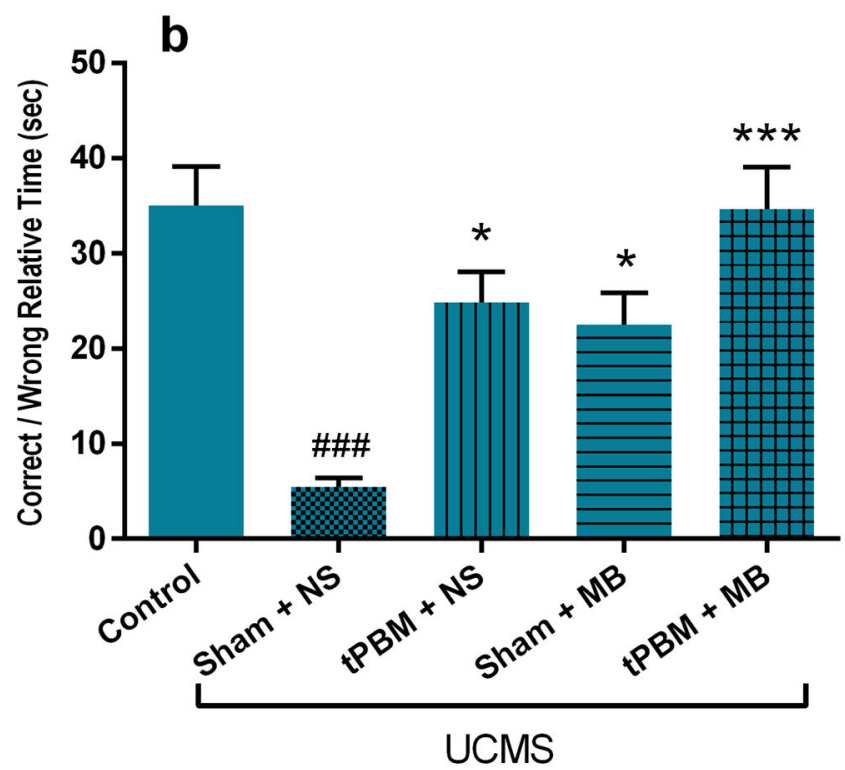

with sham + NS group. MB, methylene blue; NS, normal saline; tPBM, transcranial photobiomodulation; UCMS, unpredictable chronic mild stress 


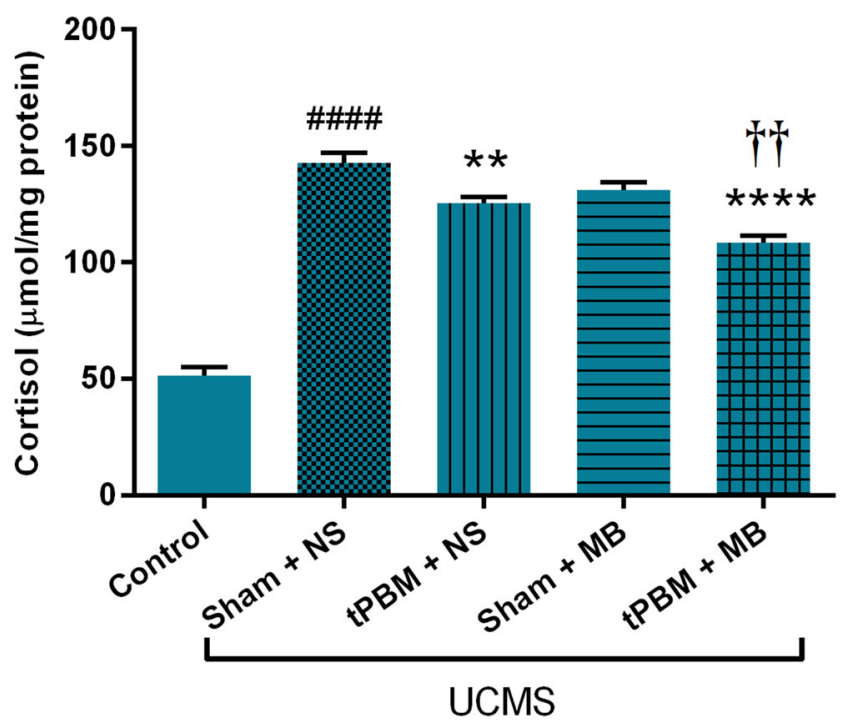

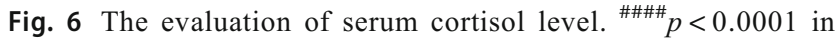
comparison with control animals and $* * p<0.01$ and $* * * * p<0.0001$ compared with sham + NS group and ${ }^{\dagger \dagger} p<0.01$ in comparison with single treatments. MB, methylene blue; NS, normal saline; tPBM, transcranial photobiomodulation; UCMS, unpredictable chronic mild stress

brain ROS level was significantly increased in the sham + NS animals $(p<0.0001)$ when compared with controls and treatment with $\operatorname{tPBM}(p<0.001), \mathrm{MB}(p<0.01)$, and combination therapy $(p<0.0001)$, significantly decreasing ROS levels in the brain tissue. Furthermore, combination therapy significantly $(p<0.05)$ decreased brain ROS levels compared with the sham + MB group (Fig. 8a).

Fig. 7 The evaluation of nitric oxide (NO) in the brain tissue. $\#$ \#\#\# 0.0001 in comparison with control animals and $* * * p<0.001$ and $* * * * p<0.0001$ in comparison with sham + NS group. MB, methylene blue; NS, normal saline; tPBM, transcranial photobiomodulation; UCMS, unpredictable chronic mild stress

\section{Effect of tPBM and MB on total antioxidant capacity}

Results showed that treatment with $\mathrm{tPBM}$ and $\mathrm{MB}$ in the UCMS-received animals had a significant effect on TAC. A number of comparisons between groups indicated that total antioxidant activity was significantly lesser than controls in the sham + NS animals $(p<0.01)$ and treatment with MB $(p<0.01)$, tPBM $(p<0.01)$, and combined therapy ( $p<0.0001$ ), significantly increasing the brain TAC (Fig. 8b).

\section{Effect of tPBM and MB on brain GPx and SOD activities}

Results revealed that animals in UCMS condition and treatment with TPBM and MB had a significant effect on brain GPx activity. Multiple comparisons between groups indicated that brain GPx activity in the sham + NS animals was significantly lower than the control animals ( $p<0.001)$, and treatment with MB and tPBM could significantly increase GPx activity $(p<0.01)$. Furthermore, the GPx activity of combination treatment was significantly $(p<0.001)$ higher than the sham + NS animals (Fig. 8c).

Results also indicated that animals in UCMS condition and treatment with $\mathrm{APBM}$ and $\mathrm{MB}$ had a significant effect on brain SOD activity. A number of comparisons between groups indicated that brain SOD activity in the sham + NS animals was significantly higher than in the controls $(p<0.05)$, and treatment with $\mathrm{MB}$ and $\mathrm{PBM}$ could significantly decrease the brain SOD activity raised by UCMS $(p<0.01)$. The combined treatment with $\mathrm{MB}$ and $\mathrm{TPBM}$ was capable of decreasing the

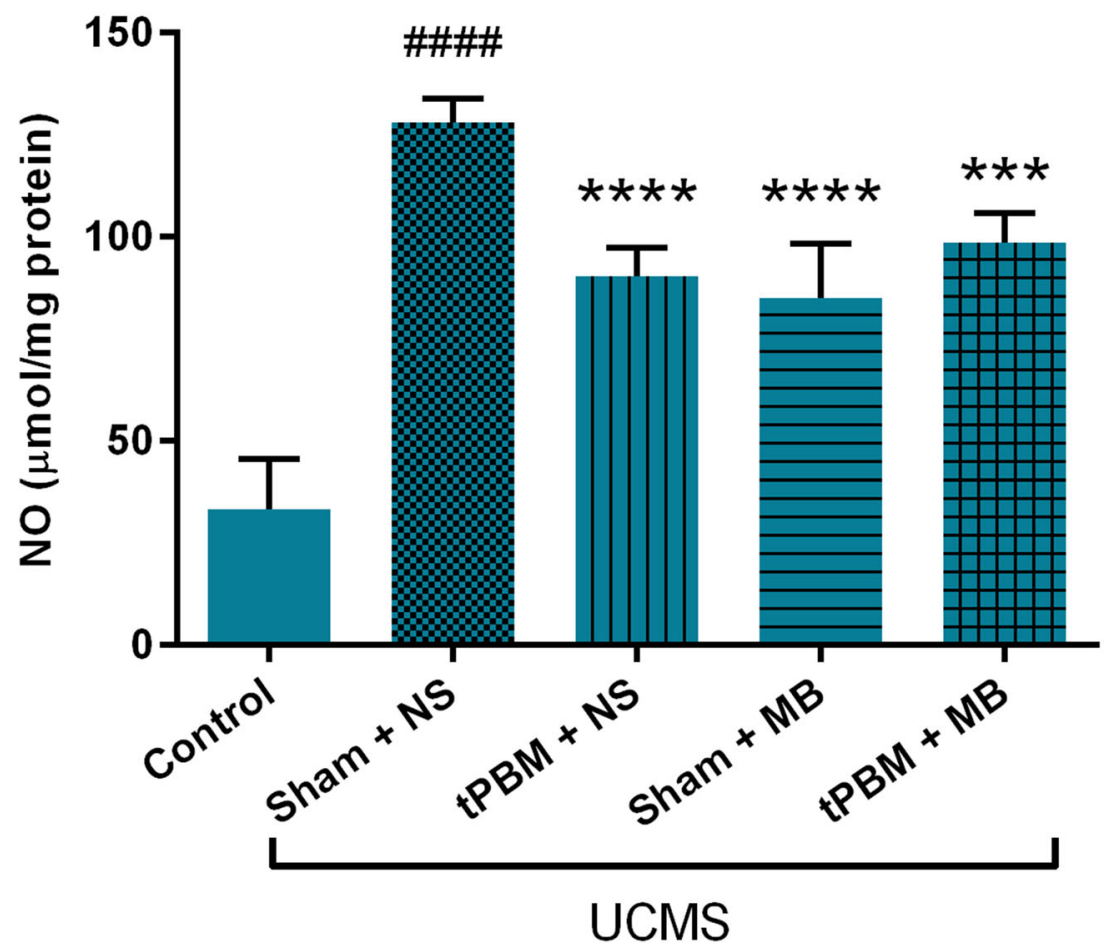


a

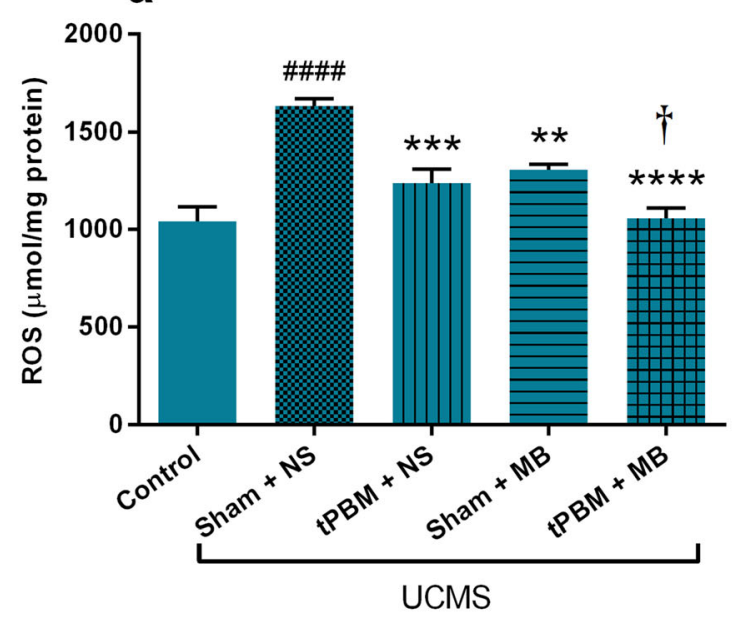

C

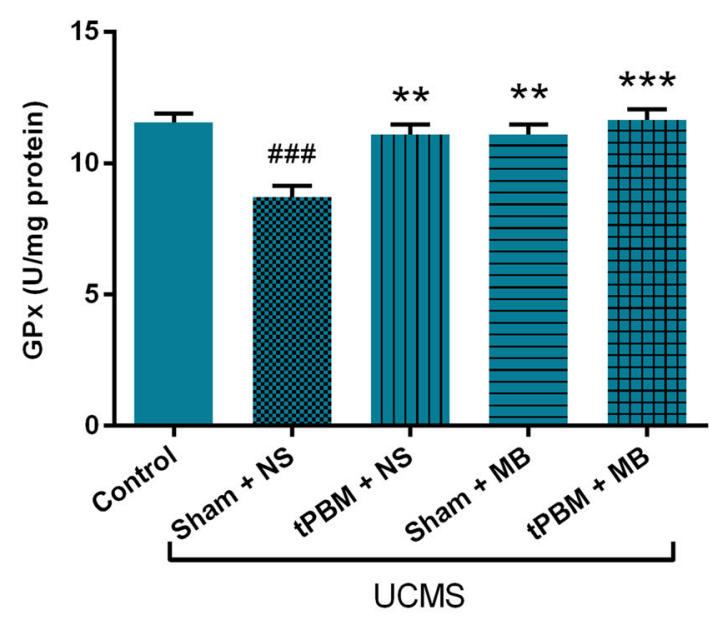

Fig. 8 The evaluation of a ROS, $\mathbf{b}$ TAC levels, and $\mathbf{c}$ GPx and $\mathbf{d}$ SOD activities in the brain tissue. ${ }^{\#} p<0.05,{ }^{\# \#} p<0.01,{ }^{\# \#} p<0.001$, and \#\#\#\# $p<0.0001$ compared with the control animals, $* * p<0.01$, $* * * p<0.001$, and $* * * * p<0.0001$ in comparison with sham + NS group and ${ }^{\dagger} p<0.05$ in comparison with sham $+\mathrm{MB}$ group. MB,

SOD activities in the brain tissue more significantly $(p<0.001)$ (Fig. 8d).

\section{Discussion}

Despite the promising studies on the benefits of tPBM and $\mathrm{MB}$, the combined effects and underlying mechanisms of these treatments are not understood precisely. The combination treatments can enhance both time and efficiency of therapy. In this study, a conventional UCMS animal model was used to determine the effect of $\mathrm{PBBM}$ and MB on anxiety-like behaviors, spatial and episodic memories, and antioxidative activities. Our results indicated that $\mathrm{PBM}$ and $\mathrm{MB}$ and their combination were beneficial in treating UCMS-induced anxiety-like behaviors, learning and memory impairments, brain

\section{b}
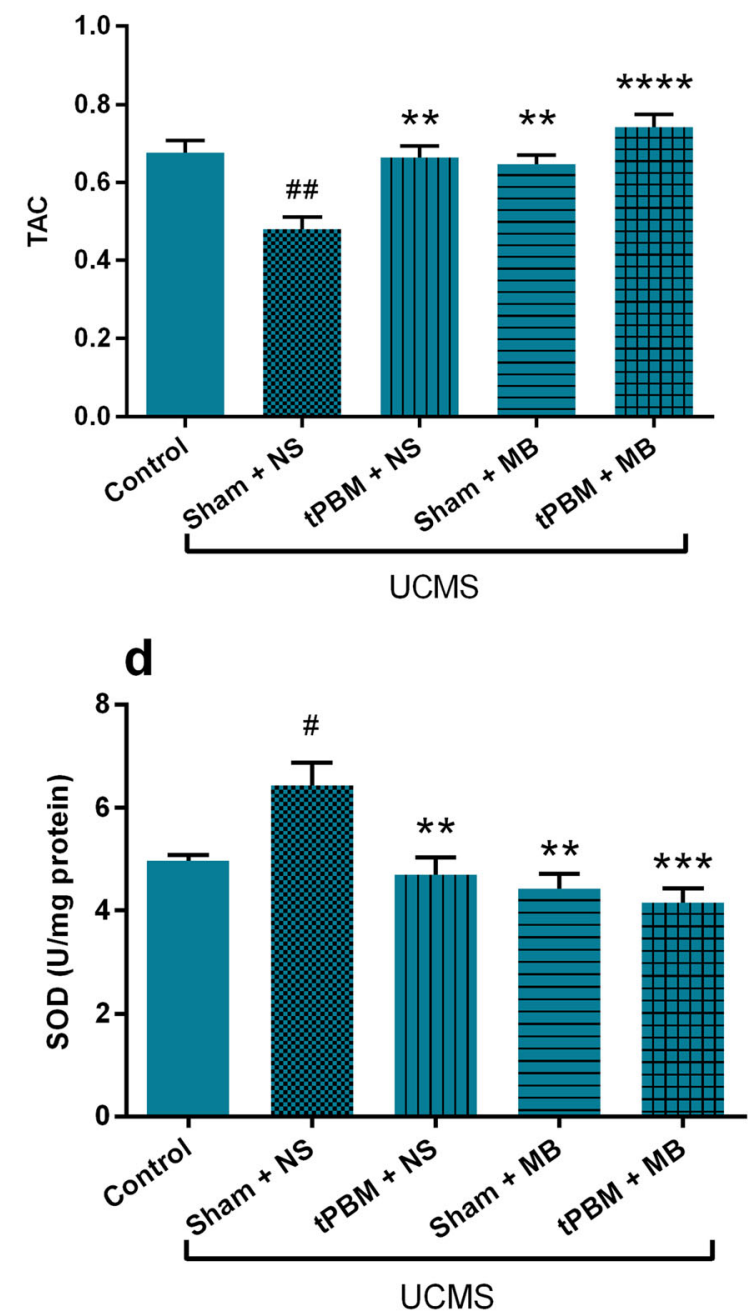

methylene blue; NS, normal saline; tPBM, transcranial photobiomodulation; UCMS, unpredictable chronic mild stress; ROS, reactive oxygen species; TAC, total antioxidant capacity; GPx, glutathione peroxidase; SOD, superoxide dismutase

oxidative stress, and NO production, as well as serum cortisol levels.

Decreased \%OAT and \%OAE in EPM test and increased serum levels of cortisol in the sham + NS group indicated anxiety induction in these animals. Animals' performance in the Barnes maze task was also impaired, which confirmed spatial memory disturbance. These changes, however, were significantly reversed by $\mathrm{TPBM}$ and MB treatments alone or in combination.

This study also indicated that UCMS induction increased brain NO levels and tPBM and MB treatment alone or in combination decreased $\mathrm{NO}$ production. It has been shown that $\mathrm{NO}$ is excessively and permanently synthesized in the brain during stress [3]. In addition, the concentration of NO in the hypothalamus has largely linked to the development of learning and memory performances [29]. On the other hand, these 
effects become predominant when the low concentration of NO is produced. In this respect, remarkable memory impairment has been observed due to a large increase in the concentration of NO in rats' brain [30].

The mitochondrial respiratory chain is located in the inner mitochondrial membrane [31]. Mitochondrial respiratory chain complexes show less activity after CMS in the brain [32]. Highly reactive radicals can harm proteins, lipids, and DNA in the mitochondria [33], which subsequently causes dysfunction of complex I or III [34] and results in metabolic oxidative stress as well as cellular damage [35]. Low-dose $\mathrm{MB}$ and PBM stimulate mitochondrial respiration by donating electrons and photons respectively to the electron transport chain [1]. These donating of electrons and photons results in better function of the respiratory chain and lesser production of free radicals (Fig. 9).

The present study also showed that UCMS induction decreased GPx activity and TAC and increased ROS levels in the brain tissue, while $\mathrm{TPBM}$ and $\mathrm{MB}$ inhibited ROS production induced by UCMS. The major consequences of oxidative stress in a living cell is the production of ROS and reduction in the antioxidant concentration [36]. There is an obvious inconsistency in the literature about the effect of PBM on ROS production. Some studies in diverse cell types have reported the generation of ROS after PBM [37]. However, other studies have shown the reduction of ROS concentration and amelioration of oxidative stress [38]. Delivering an optimum dose of the laser light to unstressed normal cells in culture results in the production of ROS in mitochondria and a rise in mitochondrial membrane potential (MMP) [37, 39]. Conversely, a rise in ROS concentration is also related to a reduction in MMP when mitochondrial inhibitors or oxidative stressors are employed [40]. In the former example, the irradiation of laser to the cells results in an elevation of MMP and consequently the reduced generation of ROS by the mitochondria.
SOD and GPx are the most important antioxidant enzymes that act as the pioneer of an antioxidant defense system against ROS during oxidative damage and have an essential role in cognitive functions [41]. Scientists have recently focused on the role of GPx deficit in the pathophysiology of stressed conditions. In one study, a lower GPx activity was observed in stressed animals compared with the controls [42]. In another study, patients with affective disorders had a lower GPx activity compared with controls [43]. Poor GPx activity can result in weakened protection against oxidants and therefore noticeable damage to membrane fatty acids and functional proteins which in turn results in neurotoxic damage associated with persistent or severe illness [44].

SOD is known as one of the main antioxidant enzymes. However, the results of studies on stressed conditions are not consistent. Some studies stated that the activity of SOD is low under stressed conditions $[45,46]$. However, one study reported a raised SOD activity associated with the intensity of depression [47]. Patients with depression have greater SOD1 activity than the healthy controls during the acute phase of illness [48]. In addition, the augmented activity of SOD has been reported in the prefrontal cortex of patients with depressive disorder [49]. It seems that an elevated level of SOD activity is a mechanism by defense system against an increased level of free radicals such as ROS in stressed conditions. At the first glance, this seems to be a contradictory result. The stage or duration of illness could be an important factor to explain the variances in this contradictory outcome [50]. In addition, SOD serves to catalyze the removal of the toxic superoxide radical [51]. Therefore, greater activity of SOD in depressed patients is possibly associated with higher concentration of oxidative mediators. Moreover, there might be a biphasic response in the generation of ROS that is the cause of variances between studies [50]. According to previous studies, larger amounts of GPx and SOD and
Fig. 9 Schematic of tPBM and MB therapeutic effects on the respiratory chain and mechanisms in the brain. NIR, near infrared; $\mathrm{MB}$, methylene blue. The figure was created in the Mind the Graph platform, www.mindthegraph. com

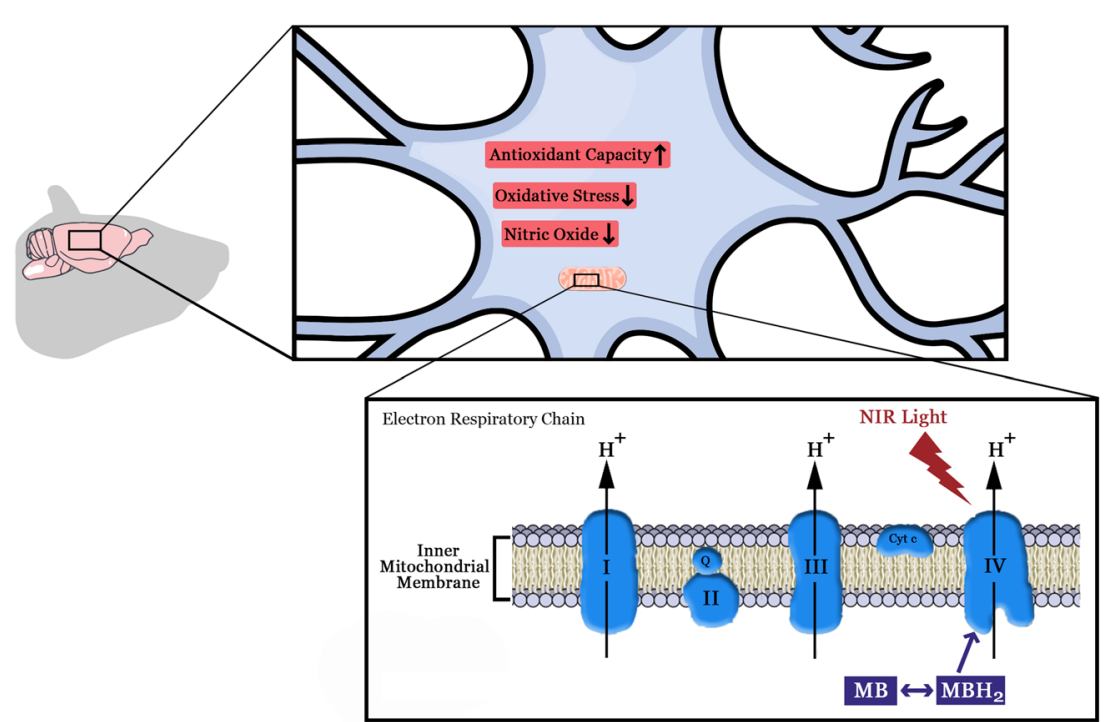


improvement in learning and memory performance were observed in sleep-deprived animals after tPBM when compared with controls [9]. Combined therapy with tPBM and coenzyme $\mathrm{Q}_{10}$ also has the potentiality to reverse GPx and SOD levels to normal conditions in stressed animals [52].

In this study, the therapeutic effects of combination treatment in most measurements were as similar as the single treatments possibly because the single therapies fully brought back the harmful effects of UCMS to control levels. This phenomenon was observed in some other studies. For example, in a study by Dong et al., when ROS and ATP levels of hippocampus were measured after single or combined treatments with LLLT and/or pyruvate-lactate in traumatic brain injury model of mice, the levels of ATP in combined groups were fully backed to control levels and were also significantly different with single treatments. But the levels of ROS in all treatment groups (including LLLT, pyruvate, lactate, and their combinations) was the same as the control group, and there was no significant difference between single and combined treatments [12]. In another study by Salehpour et al., no significant difference was observed in levels of GPx, SOD, and TAC between single and combined treatments with PBM and coenzyme Q10 maybe because single therapy was fully brought back to control levels [52]. In our study, no significant difference was observed between single and combined therapy rather than the serum cortisol level and ROS probably because the single therapies were capable of completely treating the harmful effects of UCMS. This might also be related to the type of stress model and the dosage of each of the single therapies that are used in this study. More combination studies with different dosages in neuropsychological disorders are necessary to discover the hidden aspects and the establishment of this method.

Acknowledgments This article was derived from the MSc dissertation of Mr. Reza Meynaghizadeh-Zargar.

\section{The list of abbreviations}

$\begin{array}{ll}\text { PBM } & \text { photobiomodulation } \\ \text { tPBM } & \text { transcranial photobiomodulation } \\ \text { PW } & \text { pulsed wave } \\ \text { NIR } & \text { near-infrared } \\ \text { MB } & \text { methylene blue } \\ \text { UCMS } & \text { unpredictable chronic mild stress } \\ \text { EPM } & \text { elevated plus maze } \\ \text { NOR } & \text { novel object recognition test } \\ \text { MWM } & \text { Morris water maze } \\ \text { TAE } & \text { the total arm entries } \\ \text { OAT } & \text { time spent in open arms } \\ \text { DI } & \text { discrimination index } \\ \text { NS } & \text { normal saline } \\ \text { NO } & \text { nitric oxide } \\ \text { ROS } & \text { reactive oxygen species } \\ \text { GPx } & \text { glutathione peroxidase }\end{array}$

$\begin{array}{ll}\text { SOD } & \text { superoxide dismutase } \\ \text { TAC } & \text { total antioxidant capacity } \\ \text { ETC } & \text { electron transport chain } \\ \text { BBB } & \text { blood-brain barrier } \\ \text { COX } & \text { cytochrome c oxidase } \\ \text { ATP } & \text { adenosine triphosphate } \\ \text { MMP } & \text { mitochondrial membrane potential } \\ \text { ELISA } & \text { enzyme-linked immunosorbent assay } \\ \text { DCFDA } & \text { dichlorohydrofluorescein diacetate } \\ \text { PBS } & \text { phosphate-buffered saline } \\ \text { SEM } & \text { standard error of the mean } \\ \text { ANOVA } & \text { analysis of variance } \\ \text { TUMS } & \text { Tabriz University of Medical Sciences } \\ \text { NIH } & \text { National Institutes of Health }\end{array}$

Funding information The present study was supported by Neurosciences Research Center of Tabriz University of Medical Sciences (grant number, 58471).

\section{Compliance with ethical standards}

Conflict of interest The authors declare that they have no conflict of interest.

Ethical approval All procedures of the study were conducted in accordance with the ethical guidelines set by Regional Ethics Committee of TUMS (No. IR.TBZMED.REC.1396.864) which completely coincides with the "National Institutes of Health $(\mathrm{NIH})$ Guide for the Care and Use of Laboratory Animals" (NIH; Publication No. 85-23, revised 1985).

Open Access This article is distributed under the terms of the Creative Commons Attribution 4.0 International License (http:// creativecommons.org/licenses/by/4.0/), which permits unrestricted use, distribution, and reproduction in any medium, provided you give appropriate credit to the original author(s) and the source, provide a link to the Creative Commons license, and indicate if changes were made.

\section{References}

1. Gonzalez-Lima F, Auchter A (2015) Protection against neurodegeneration with low-dose methylene blue and near-infrared light. Front Cell Neurosci 9(179). https://doi.org/10.3389/fncel.2015. 00179

2. Xuan W, Vatansever F, Huang L, Hamblin MR (2014) Transcranial low-level laser therapy enhances learning, memory, and neuroprogenitor cells after traumatic brain injury in mice. J Biomed Opt 19(10):108003-108003. https://doi.org/10.1117/1. JBO.19.10.108003

3. Madrigal JL, Moro MA, Lizasoain I, Lorenzo P, Castrillo A, Boscá L, Leza JC (2001) Inducible nitric oxide synthase expression in brain cortex after acute restraint stress is regulated by nuclear factor kB-mediated mechanisms. J Neurochem 76(2):532-538. https:// doi.org/10.1046/j.1471-4159.2001.00108.x

4. Yan C, Huang D, Zhang Y (2011) The involvement of ROS overproduction and mitochondrial dysfunction in PBDE-47-induced apoptosis on Jurkat cells. Exp Toxicol Pathol 63(5):413-417. https://doi.org/10.1016/j.etp.2010.02.018 
5. Wang J, Yuan J, Pang J, Ma J, Han B, Geng Y, Shen L, Wang H, Ma Q, Wang Y (2016) Effects of chronic stress on cognition in male SAMP8 mice. Cell Physiol Biochem 39(3):1078-1086. https://doi. org/10.1159/000447816

6. Hamblin MR, Agrawal T, de Sousa M (2016) Handbook of lowlevel laser therapy. CRC Press, Boca Raton

7. Hennessy M, Hamblin MR (2016) Photobiomodulation and the brain: a new paradigm. J Opt 19(1):013003. https://doi.org/10. 1088/2040-8986/19/1/013003

8. Hamblin MR (2016) Shining light on the head: photobiomodulation for brain disorders. BBA clinical 6:113-124. https://doi.org/10.1016/j.bbacli.2016.09.002

9. Salehpour F, Farajdokht F, Erfani M, Sadigh-Eteghad S, Shotorbani SS, Hamblin MR, Karimi P, Rasta SH, Mahmoudi JJB (2018) Transcranial near-infrared photobiomodulation attenuates memory impairment and hippocampal oxidative stress in sleep-deprived mice. Brain Res 1682:36-43. https://doi.org/10.1016/j.brainres. 2017.12.040

10. da Luz EC, Salgado ASI, Zângaro RA, da Silva Pereira MC, Kerppers II, da Silva LA, Parreira RB (2017) Transcranial LED therapy on amyloid- $\beta$ toxin $25-35$ in the hippocampal region of rats. Lasers Med Sci 32(4):749-756. https://doi.org/10.1007/ s10103-017-2156-3

11. Eshaghi E, Sadigh-Eteghad S, Mohaddes G, Rasta SH (2019) Transcranial photobiomodulation prevents anxiety and depression via changing serotonin and nitric oxide levels in brain of depression model mice: a study of three different doses of $810 \mathrm{~nm}$ laser. Lasers Surg Med. https://doi.org/10.1002/lsm.23082

12. Dong T, Zhang Q, Hamblin MR, Wu MXJJCBF, Metabolism (2015) Low-level light in combination with metabolic modulators for effective therapy of injured brain. J Cereb Blood Flow Metab 35(9):1435-1444. https://doi.org/10.1038/jcbfm.2015.87

13. Otterço A, Brassolatti P, Andrade A, Avó L, Bossini P, Parizotto N (2018) Effect of photobiomodulation $(670 \mathrm{~nm})$ associated with vitamin a on the inflammatory phase of wound healing. Lasers Med Sci 33(9):1867-1874. https://doi.org/10.1007/s10103-018-2535-4

14. Moradi A, Kheirollahkhani Y, Fatahi P, Abdollahifar M-A, Amini A, Naserzadeh P, Ashtari K, Ghoreishi SK, Chien S, Rezaei F (2018) An improvement in acute wound healing in mice by the combined application of photobiomodulation and curcuminloaded iron particles. Lasers Med Sci:1-13. https://doi.org/10. 1007/s10103-018-2664-9

15. Hwang J, Castelli DM, Gonzalez-Lima F (2016) Cognitive enhancement by transcranial laser stimulation and acute aerobic exercise. Lasers Med Sci 31(6):1151-1160. https://doi.org/10.1007/ s10103-016-1962-3

16. Xiong ZM, Choi JY, Wang K, Zhang H, Tariq Z, Wu D, Ko E, LaDana C, Sesaki H, Cao K (2016) Methylene blue alleviates nuclear and mitochondrial abnormalities in progeria. Aging Cell 15(2):279-290. https://doi.org/10.1111/acel.12434

17. Gonzalez-Lima F, Barksdale BR, Rojas JC (2014) Mitochondrial respiration as a target for neuroprotection and cognitive enhancement. Biochem Pharmacol 88(4):584-593. https://doi.org/10.1016/ j.bcp.2013.11.010

18. Callaway NL, Riha PD, Bruchey AK, Munshi Z, Gonzalez-Lima F (2004) Methylene blue improves brain oxidative metabolism and memory retention in rats. Pharmacol Biochem Behav 77(1):175181. https://doi.org/10.1016/j.pbb.2003.10.007

19. Riha PD, Bruchey AK, Echevarria DJ, Gonzalez-Lima F (2005) Memory facilitation by methylene blue: dose-dependent effect on behavior and brain oxygen consumption. Eur J Pharmacol 511(23):151-158. https://doi.org/10.1016/j.ejphar.2005.02.001

20. Gonzalez-Lima F, Valla J, Jorandby L (1998) Cytochrome oxidase inhibition in Alzheimer's disease. Springer, Berlin, pp 171-201

21. Li L, Yang R, Li P, Lu H, Hao J, Li L, Tucker D, Zhang QJM (2018) Combination treatment with methylene blue and hypothermia in global cerebral ischemia. Mol Neurobiol 55(3):2042-2055. https://doi.org/10.1007/s12035-017-0470-1

22. Salehpour F, Ahmadian N, Rasta SH, Farhoudi M, Karimi P, Sadigh-Eteghad S (2017) Transcranial low-level laser therapy improves brain mitochondrial function and cognitive impairment in D-galactose-induced aging mice. Neurobiol Aging 58:140-150. https://doi.org/10.1016/j.neurobiolaging.2017.06.025

23. Auchter A, Williams J, Barksdale B, Monfils MH, Gonzalez-Lima F (2014) Therapeutic benefits of methylene blue on cognitive impairment during chronic cerebral hypoperfusion. J Alzheimers Dis 42(s4):525-535. https://doi.org/10.3233/JAD-141527

24. Ateş GB, Ak A, Garipcan B, Gülsoy M (2017) Methylene blue mediated photobiomodulation on human osteoblast cells. Lasers Med Sci 32(8):1847-1855. https://doi.org/10.1007/s10103-0172286-7

25. Patel S, Hillard CJ (2006) Pharmacological evaluation of cannabinoid receptor ligands in a mouse model of anxiety: further evidence for an anxiolytic role for endogenous cannabinoid signaling. J Pharmacol Exp Ther 318(1):304-311. https://doi.org/10.1124/jpet. 106.101287

26. Farajpour R, Sadigh-Eteghad S, Ahmadian N, Farzipour M, Mahmoudi J, Majdi A (2017) Chronic administration of Rosa canina hydro-alcoholic extract attenuates depressive-like behavior and recognition memory impairment in diabetic mice: a possible role of oxidative stress. Med Princ Pract 26(3):245-250. https://doi. org/10.1159/000464364

27. Pourmemar E, Majdi A, Haramshahi M, Talebi M, Karimi P, Sadigh-Eteghad S (2017) Intranasal cerebrolysin attenuates learning and memory impairments in D-galactose-induced senescence in mice. Exp Gerontol 87:16-22. https://doi.org/10.1016/j.exger. 2016.11.011

28. Nikniaz L, Mahdavi R, Ostadrahimi A, Hejazi MA, Vatankhah AM (2013) Effects of synbiotic supplementation on total antioxidant capacity of human breastmilk. Breastfeed Med 8(2):217-222. https://doi.org/10.1089/bfm.2012.0078

29. Garthwaite J, Boulton CL (1995) Nitric oxide signaling in the central nervous system. Annu Rev Physiol 57:683-706. https://doi.org/ 10.1146/annurev.ph.57.030195.003343

30. dos Reis EA, de Oliveira LS, Lamers ML, Netto CA, Wyse AT (2002) Arginine administration inhibits hippocampal $\mathrm{Na}(+), \mathrm{K}(+)-$ ATPase activity and impairs retention of an inhibitory avoidance task in rats. Brain Res 951(2):151-157. https://doi.org/10.1016/ S0006-8993(02)03077-9

31. Douarre C, Sourbier C, Dalla Rosa I, Das BB, Redon CE, Zhang H, Neckers L, Pommier Y (2012) Mitochondrial topoisomerase I is critical for mitochondrial integrity and cellular energy metabolism. PLoS One 7(7):e41094

32. Rezin GT, Cardoso MR, Gonçalves CL, Scaini G, Fraga DB, Riegel RE, Comim CM, Quevedo J, Streck EL (2008) Inhibition of mitochondrial respiratory chain in brain of rats subjected to an experimental model of depression. Neurochem Int 53(6-8):395-400

33. Van Houten B, Woshner V, Santos JH (2006) Role of mitochondrial DNA in toxic responses to oxidative stress. DNA repair 5(2):145152

34. Castro MR, Suarez E, Kraiselburd E, Isidro A, Paz J, Ferder L, Ayala-Torres S (2012) Aging increases mitochondrial DNA damage and oxidative stress in liver of rhesus monkeys. Exp Gerontol 47(1):29-37

35. Hollensworth SB, Shen C-C, Sim JE, Spitz DR, Wilson GL, LeDoux SP (2000) Glial cell type-specific responses to menadione-induced oxidative stress. Free Radic Biol Med 28(8): 1161-1174

36. Rinwa P, Kumar A (2013) Quercetin suppress microglial neuroinflammatory response and induce antidepressent-like effect in olfactory bulbectomized rats. Neuroscience. 255:86-98. https:// doi.org/10.1016/j.neuroscience.2013.09.044 
37. Chen AC, Arany PR, Huang Y-Y, Tomkinson EM, Sharma SK, Kharkwal GB, Saleem T, Mooney D, Yull FE, Blackwell TS (2011) Low-level laser therapy activates NF-kB via generation of reactive oxygen species in mouse embryonic fibroblasts. PLoS One 6(7):e22453. https://doi.org/10.1371/journal.pone.0022453

38. Silveira PCL, Silva LA, Freitas TP, Latini A, Pinho RA (2011) Effects of low-power laser irradiation (LPLI) at different wavelengths and doses on oxidative stress and fibrogenesis parameters in an animal model of wound healing. Lasers Med Sci 26(1):125131. https://doi.org/10.1007/s10103-010-0839-0

39. Gavish L, Asher Y, Becker Y, Kleinman Y (2004) Low level laser irradiation stimulates mitochondrial membrane potential and disperses subnuclear promyelocytic leukemia protein. Lasers Surg Med 35(5):369-376. https://doi.org/10.1002/1sm.20108

40. Satoh T, Enokido Y, Aoshima H, Uchiyama Y, Hatanaka H (1997) Changes in mitochondrial membrane potential during oxidative stress-induced apoptosis in PC12 cells. J Neurosci Res 50(3):413420. https://doi.org/10.1002/(SICI)1097-4547(19971101)50: 3<413::AID-JNR7>3.0.CO;2-L

41. Huang T-T, Leu D, Zou Y (2015) Oxidative stress and redox regulation on hippocampal-dependent cognitive functions. Arch Biochem Biophys 576:2-7. https://doi.org/10.1016/j.abb.2015.03. 014

42. Samarghandian S, Azimi-Nezhad M, Borji A, Samini M, Farkhondeh TJB, medicine a (2017) Protective effects of carnosol against oxidative stress induced brain damage by chronic stress in rats. BMC COMPLEM ALTERN M 17(1):249. https://doi.org/10. 1186/s12906-017-1753-9

43. Ozcan ME, Gulec M, Ozerol E, Polat R, Akyol O (2004) Antioxidant enzyme activities and oxidative stress in affective disorders. Int Clin Psychopharmacol 19(2):89-95

44. Berk M (2009) Neuroprogression: pathways to progressive brain changes in bipolar disorder. Int J Neuropsychopharmacol 12(4): 441-445. https://doi.org/10.1017/S1461145708009498

45. García-Díaz EC, Gómez-Quiroz LE, Arenas-Ríos E, AragónMartínez A, Ibarra-Arias JA, Retana-Márquez MS (2015) Oxidative status in testis and epididymal sperm parameters after acute and chronic stress by cold-water immersion in the adult rat. Syst Biol Reprod Med 61(3):150-160. https://doi.org/10.3109/ 19396368.2015.1008071
46. Mocelin R, Marcon M, D'ambros S, Mattos J, Sachett A, Siebel AM, Herrmann AP, Piato A (2018) N-Acetylcysteine reverses anxiety and oxidative damage induced by unpredictable chronic stress in zebrafish. MOL NEUROBIOL:1-8. https://doi.org/10.1007/ s12035-018-1165-y

47. Sarandol A, Sarandol E, Eker SS, Erdinc S, Vatansever E, Kirli S (2007) Major depressive disorder is accompanied with oxidative stress: short-term antidepressant treatment does not alter oxidative-antioxidative systems. HUM PSYCHOPHARM CLIN. 22(2):67-73. https://doi.org/10.1002/hup.829

48. Gałecki P, Szemraj J, Bieńkiewicz M, Zboralski K, Gałecka E (2009) Oxidative stress parameters after combined fluoxetine and acetylsalicylic acid therapy in depressive patients. HUM PSYCHOPHARM CLIN 24(4):277-286. https://doi.org/10.1002/ hup. 1014

49. Michel TM, Frangou S, Thiemeyer D, Camara S, Jecel J, Nara K, Brunklaus A, Zoechling R, Riederer P (2007) Evidence for oxidative stress in the frontal cortex in patients with recurrent depressive disorder - a postmortem study. Psychiatry Res 151(1):145-150. https://doi.org/10.1016/j.psychres.2006.04.013

50. Maes M, Mihaylova I, Kubera M, Uytterhoeven M, Vrydags N, Bosmans E (2010) Increased plasma peroxides and serum oxidized low density lipoprotein antibodies in major depression: markers that further explain the higher incidence of neurodegeneration and coronary artery disease. J Affect Disord 125(1):287-294. https://doi. org/10.1016/j.jad.2009.12.014

51. Tainer JA, Getzoff ED, Richardson JS, Richardson DC (1983) Structure and mechanism of copper, zinc superoxide dismutase. Nature. 306(5940):284. https://doi.org/10.1038/306284a0

52. Salehpour F, Farajdokht F, Cassano P, Sadigh-Eteghad S, Erfani M, Hamblin MR, Salimi MM, Karimi P, Rasta SH, Mahmoudi JJB (2018) Near-infrared photobiomodulation combined with coenzyme Q10 for depression in a mouse model of restraint stress: reduction in oxidative stress, neuroinflammation, and apoptosis. Brain Res Bull. https://doi.org/10.1016/j.brainresbull.2018.10.010

Publisher's note Springer Nature remains neutral with regard to jurisdictional claims in published maps and institutional affiliations. 